Kohl: a Journal for Body and Gender Research

Vol. 4, No. 2 (Winter 2018)

\title{
Diagnosis: Chronic Patriarchy
}

\author{
Islam Khatib
}




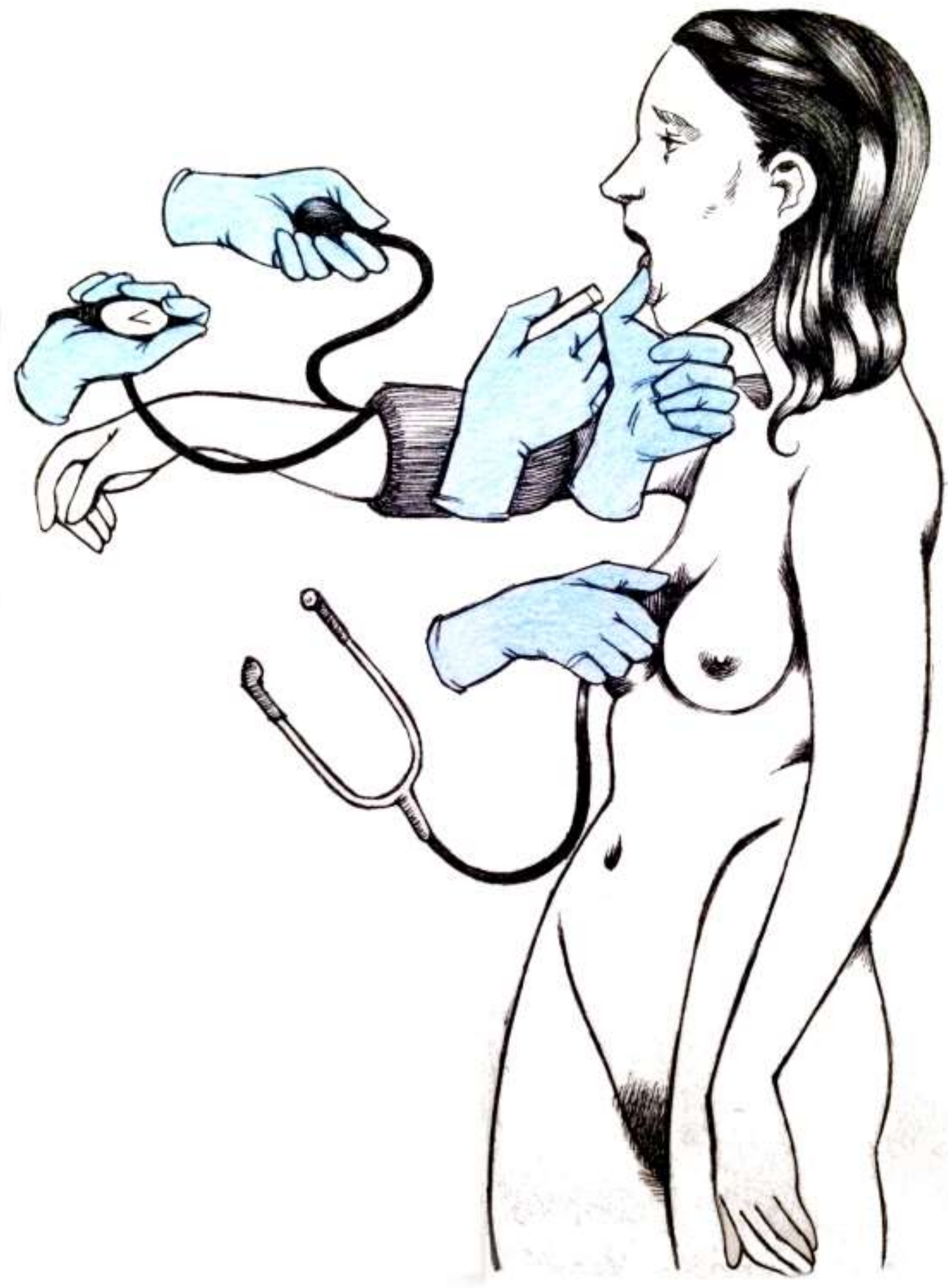

On Medical Patriarchy by Islam Khatib (2018) 


\section{Hello, my friend got a Pap smear last week.}

What is your reaction when you read this?

I know, nobody wants to hear about the private matters of women's health. Underline private. They are private, because they are about disgusting "female genitalia." The reactions to women's bodies are simply ridiculous. We learn to hate our bodies; we learn to know them through the epistemological monopoly of a few elite male doctors. I hate the very thought of women going to get a Pap smear, even if they are an annual necessity. Even the way doctors examine our insides seems like an invasion of our personal space. But nothing compares to the invasiveness of their questions about our sex lives.

\section{"Are you married?"}

Despite their genius, doctors could not find another way to determine whether a woman has an abnormal growth in the uterus. They stretch the vagina with a heavy speculum, project a beam of light to stare at it, take swabs from the cervix, put their hands inside it, all the while asking nasty questions. To add insult to injury, they expect you not to stress, to relax, surrender, and breathe.

I read a lot about how the medical field claimed the practices related to pregnancy and childbirth, deviating them from the expertise of women. Once a collective event that connected women to each other, pregnancy and childbirth morphed into surveillance apparatuses that watched women while they are drugged, machines that take pictures of their wombs, and surgeries that determine the health of the fetus at the expense of the mother's mental and physical health. The frightening number of women who undergo unsafe caesarean sections is recently on the rise. In fact, C-sections are clearly used by doctors and hospitals to exploit refugee women. For example, Syrian refugees in Lebanon are forced to undergo expensive caesarean sections in order to obtain UNHCR support. At the same time, hospitals rip them off by doubling the cost of these surgeries for refugee women. Andrea Dworkin describes these interventions as sexual violence against women, with the aim of maintaining the vagina intact, or "tight," for the sexual pleasure of men. (I do not fully agree with this - C-sections may be the optimal or only option in some cases. The underlying problem is not the surgery itself as much as it is the absence of women's choices. However, the description is worthy of consideration).

Women's historical knowledge about their bodies is now monopolized by a male-dominated profession. This knowledge is no longer free and available, and accessing it comes at a price. Even when such access is given, this knowledge remains incomplete because it is based on the study of male bodies. And these bodies are already disciplined by military institutions, prison systems, or concentration camps. In other words, even (male) bodies understood as normative are subject to inevitable social forces, such as poverty and racism. We learn that the body of a man who expresses his manhood in a white, tall, graceful, and physically capable or "healthy" way is the standard and basis of medicine. This has led to the loss of the traditional knowledge transmitted by midwives, doulas, and women who practice herbal medicine. It is those women who have 
been burnt, suspended, killed, maimed, and called witches, ${ }^{1}$ and whom we know by strange names we've encountered in Arab soap operas.

Medical patriarchy has played a pivotal role in enhancing the idea of biological imperatives between "women" and "men." Despite that, medicine refuses to study the bodies of women. Until 1994, women were excluded from medical research trials, as the "proper" male body is the only standard deemed acceptable for biological knowledge.

Our bodies are a perversion to what is natural and acceptable. They are only important as long as they are controlled and disciplined to be of better service to the patriarchal system, through mating, marriage, and free sexual services. Our bodies are treated like cattle that has no worth aside from its reproductive function and free labor. Medicine's approach to women's bodies is one of exploitation until they are no longer functional. We are prevented from taking control over our bodies and enjoying our individual lives if they do not benefit the "head of the house" in one way or another.

The problem is that the doctors think they are judges in a beauty pageant when we visit their clinics. They take a look at our bodies, inform us of what is wrong with their shape, then suggest a way to solve the problem.

\section{Me: Hello! \\ I suddenly faint and - Doctor: Wait, did you try to lose a bit of weight?}

At any given time, one can find countless of women in the waiting rooms of these clinics who would do without being judged by these doctors. But regardless, they act as if we are paying them this amount of money which is very hard to come by - to evaluate our bodies and their shapes, to "fix the mistake," to cut off the meat, to absorb the fat, to implant, to decrease, to fill... But dear doctor, I am here to ask about diabetes, cholesterol, and cancer.

When we refer to "medical patriarchy," we are not creating complicated jargon, but giving a name to what most women live so they can make use of it in moments of resentment. My mother has to sit through unsolicited comments about her body every time she visits the ophthalmologist. Our neighbor tries to explain to her dentist that her big nose does not affect her life as much as he thinks. And I am happy, even if my weight surpasses what is "allowed," so there is no need for my orthopedist to prescribe me antidepressants.

${ }^{1}$ The A Project translated the book Witches, Midwives, and Nurses: A History of Women Healers to Arabic. 